International Research Journal of Management, IT \& Social Sciences
Available online at https://sloap.org/journals/index.php/irjmis/
Vol. 6 No. 5, September 2019, pages: 95 100
ISSN: 2395-7492
https://doi.org/10.21744/irjmis.v6n5.710

\title{
Dyscalculia and Pedagogical Intervention
}

\author{
Mariela Alexandra Calderón Delgado ${ }^{a}$ \\ Ronald Iván Zamora Delgado ${ }^{\text {b }}$ \\ Raphael Palma Palma ${ }^{c}$ \\ María Elena Moya ${ }^{d}$
}

Article history:

Received: 18 March 2019

Accepted: 31 May 2019

Published: 22 August 2019

\section{Keywords:}

dyscalculia;

intervention;

mathematics;

pedagogic;

significant learning;

\begin{abstract}
The acquisition of knowledge in the area of mathematics, generally requires a series of numerical competencies that are strengthening as school-age progress, this process is sometimes affected by a learning disorder called dyscalculia that it causes severe difficulties in understanding or internalizing arithmetic contents that lead to mathematical reasoning. The objective of this article is to provide relevant information on the causes of dyscalculia, repercussions on learning and the importance of early pedagogical intervention, through a descriptive study, a bibliographic review of the topic and analysis of various sources have carried out, which allowed formulating conclusions regarding the teaching and learning of mathematics. These data provided the necessary information to determine that dyscalculia is a condition that requires treatment that includes collaborative work between specialists, parents, and teachers. Early diagnosis and the use of appropriate pedagogical intervention strategies and the incorporation of innovative methodologies in the teaching-learning process will allow effective long-term results.
\end{abstract}

2395-7492@ Copyright 2019. The Author. This is an open-access article under the CC BY-SA license (https://creativecommons.org/licenses/by-sa/4.0/) All rights reserved.

\section{Author correspondence:}

Mariela Alexandra Calderón Delgado,

Educational Unit "Edwin Hernán Mendoza Bravo".

Email address: mcalderon6583@pucem.edu.ec

\section{Introduction}

Specific learning disorders significantly affect a minority group of the world's school-age population, who experience a cognitive deficit that leads to poor academic performance in certain areas. Among these disorders are those related to the difficulty in performing mathematical calculations, reading and writing.

This paper focuses on the analysis and reflection of those anomalies that affect the acquisition of numerical skills in school-age children, specifically of dyscalculia, which is a brain-type condition of neurobiological origin that hinders

${ }^{\text {a }}$ Pontifical Catholic University of Ecuador, Portoviejo, Ecuador

${ }^{\mathrm{b}}$ Pontifical Catholic University of Ecuador, Portoviejo, Ecuador

c Educational Unit "Edwin Hernán Mendoza Bravo", Portoviejo, Ecuador

${ }^{\mathrm{d}}$ Pontifical Catholic University of Ecuador, Portoviejo, Ecuador 
the ability to understand and work with numbers, processes and arithmetic contents. Some children who suffer from it have complications to understand mathematical concepts. They work hard to learn and memorize basic numerical data, they can understand what to do in math class, but not why they do it, that is, they do not understand the logic of the process (Scrich, et la., 2017).

The objective of the current research is to describe the dyscalculia learning disorder, its causes, repercussions on learning and the importance of early pedagogical intervention, through the bibliographic analysis of several sources, which allowed us to make a study and formulate conclusions with regarding the teaching of mathematics. The research background on this subject is numerous, this learning disorder has been the object of multiple studies globally, as evidenced by the studies found in the databases on the web; The social and scientific impact of this condition is evident. The present document is a contribution to the educational community and leaves the door open for further local work.

\section{Materials and Methods}

In the design of this research, he used the descriptive methodology, the method of content analysis the objective and systematic description of the subject was developed, which considered a critical and reflexive inquiry of theoretical and empirical studies related to neuropsychology and learning disorders. The bibliographic review was used where the criteria of several authors based on various theories related to learning disorders such as dyscalculia and the importance of a timely pedagogical intervention that led to the application of the inductive-deductive method for obtaining the corresponding conclusions.

\section{Results and Discussions}

\subsection{Dyscalculia}

Dyscalculia is a learning disorder that affects the ability to understand mathematical processes that prevent the calculation, is of biological, genetic or acquired origin and manifests itself with the congenital condition of the brain substrate responsible for mathematical functions. This anomaly is the product of some brain dysfunction and does not imply an alteration in the remaining cognitive processes (Portellano, 2008; Espinosa et al., 2018; Menéndez et al., 2019).

This learning disorder hinders the ability to understand and work with numbers, processes, and mathematical concepts. Some children who suffer from it have complications to understand basic concepts; generally, these children do not develop or perform activities that require the evocation of numerical information.

Multiple studies conducted through neuroimaging have allowed us to observe brain activity and through images, it has shown that the deficit in the neural connections associated with dyscalculia is in the area responsible for numerical processing that is located in the parietal lobe of the brain, specifically in the intraparietal groove (Bugden \& Ansari, 2015). The brain areas affected are specifically the regions of the left hemisphere related to linguistic and viso-spatial processing, the right parietal cortex and prefrontal areas related to attention control, and executive functions (De la Peña \& Bernabéu, 2018).

The causes of this problem, which makes, it difficult to interpret arithmetic symbols and processes typical of mathematics, have not determined exactly by researchers, but science has allowed us to identify factors that indicate that it is a brain condition that can have caused by lesions. brain, neurological and maturation alterations, which lead to problems of laterality, memory, attention, and difficulty in acquiring abstract thinking (Farnham, 2004; Meza et al., 2018; Paramita et al., 2018), several studies relate the causes of dyscalculia with literacy disorders, specifically of dyslexia, but its diagnosis is complex.

It should have noted that although it is one of the most common learning disorders, it does not have as much research as dyslexia and dysgraphia; this can be evidenced in the number of scientific papers found in the repositories published on the web.

\subsection{How to identify dyscalculia?}

The first step to take measures around the dyscalculia disorder is the diagnosis, once identified; all necessary resources should have used to try to ensure that the child achieves a better development in the educational field (García 
et al., 2016). In order to know if a child has dyscalculia, it is necessary for professionals to carry out different studies that measure the individual's abilities. The presumptive diagnoses will allow identifying the subjects with weak performance in the calculation, of those who suffer from dyscalculia. Early detection will allow more effective longterm psycho-pedagogical interventions (Balbi \& Dansilo, 2010).

It is necessary that teachers in schools, as parents at home, are pending certain manifestations of children suffering from a learning disorder related to calculus, among which are detailed: a) The individual does not achieve Correct writing and identification of numbers. b) Shows incapacity or many difficulties for the realization of sequential series or numerical classifications. c) Difficulties in executing reasoning tasks, which prevents him from interpreting sentences and solving simple mathematical problems. d) Invest, rotate or transpose the numbers. The most frequent case is to confuse 6 with 9, although there are others. e) Confuse the mathematical symbols (addition, subtraction, multiplication, division). f) Difficulty in understanding processes that lead to an analysis of position, size or relationships. g) Difficulties in space-time coordination (Rojas et al., 2011; Wiardani et al., 2018; Zambrano et al., 2018).

If a child presents several of these expressions, it must be evaluated by professionals to rule out or affirm a diagnosis of dyscalculia that avoids future inconveniences in the teaching-learning process; The earlier the detection, the more effective the intervention. The pedagogical intervention must be carried out taking into account the learning styles of each child and aimed at the work of psychological aspects related to attention, memory, and concentration (Fonseca, López, Massagué, 2018), which contribute to the creation of enriching experiences in regards to learning mathematics. It is important to note that children who do not receive adequate treatment will present academic difficulties that could result in a dropout.

\subsection{Strategies to teach children with dyscalculia}

For students who have difficulties in their academic performance due to dyscalculia. Certain action strategies aimed at improving the educational process. Involves the restructuring of planning. The classroom environment, and others must be adopted learning environments, (educational institution, home and community), through various support alternatives such as: conducting differentiated assessments with segmented instructions and including teaching materials (Ministry of Education of Ecuador, 2016), as a fundamental resource, as this will facilitate the perception and understanding of concepts in a creative way.

The use of didactic material and the incorporation of the Tic in the teaching and learning process will allow the student to understand the basic concepts of mathematics, through the approach of situations with innovative implements, which raise attention and promote the motivation of the Dyscalculic student. These types of strategies have intended for the student to learn by integrating motivation, attitudes and affection, substantial components when learning.

\subsection{Meaningful learning of mathematics}

The multiple strategies, methods, and techniques applied in the teaching processes of exact science learning, have the purpose of the student developing critical and reflective thinking in situations that involve the evocation of arithmetic processes for the resolution of problems that enable you to learn significantly for life.

But, what is meaningful learning? Meaningful learning is what occurs when the student relates the new information to his previous knowledge stored in his cognitive structure and adopts a favorable attitude towards the new learning. This process becomes complex in individuals with disorders such as dyscalculia, children who suffer from it have an innate lack of numerical sense, as well as dyslexics of phonetic awareness (Roselli \& Matute, 2011).

Delgado, M. A. C., Delgado, R. I. Z., Palma, R. P., \& Moya, M. E. (2019). Dyscalculia and pedagogical intervention. International Research Journal of Management, IT and Social Sciences, 6(5), 95-100. 
Figure 1 shows the typical errors in children with dyscalculia in the teaching-learning process, organized into seven categories.

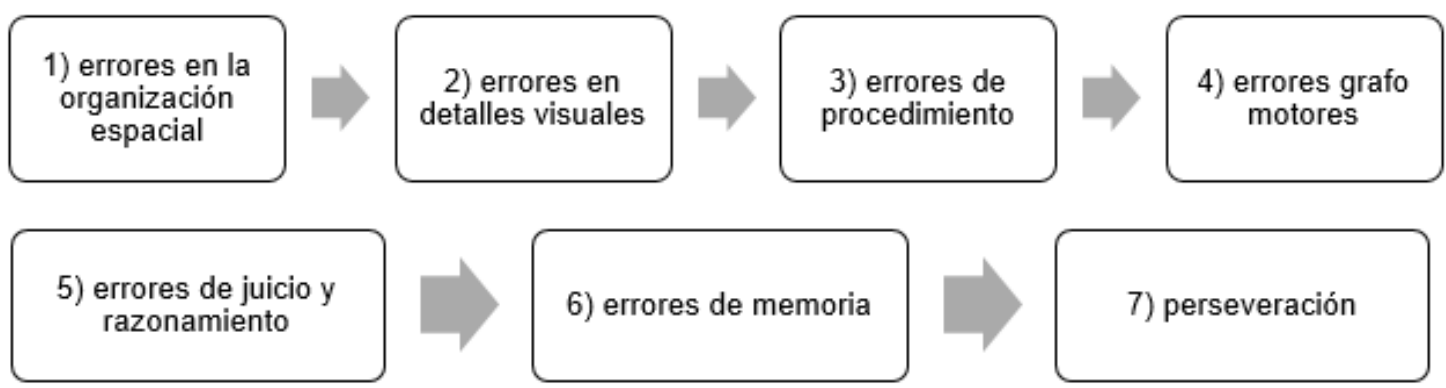

Figure 1. Typical errors in children with dyscalculia.

Source: Strang and Rourke (Ardila \& Rosselli, 2007)

To try to correct these errors and for children to learn significant mathematics, it is necessary to treat dyscalculia in a synergistic and holistic way, among the teacher, specialists, and parents, with the purpose of developing the necessary mathematical skills and according to the age of the child (Fonseca et al., 2019). Motivation in the classroom, as at home, accompanied by a timely intervention are the trigger to achieve school success.

This allows analyzing, that the manifestations of dyscalculia can vary according to the child. Although each person or individual is different there are certain errors that are commonly characteristic of the disorder and include problems to recognize, remember, order, draw and reason on numerical information, causing serious inconveniences so that these data remain in the memory for its later recall

\section{Conclusion}

Dyscalculia is a learning disorder that affects the ability to understand and perform mathematical calculations. People who suffer from it have difficulties to represent, recognize and remember numerical symbols. Its causes are not yet clarified but numerous studies relate it to genetic factors and brain lesions in specific areas.

Dyscalculia has no cure, but it is possible to treat it. Early diagnosis and the use of appropriate pedagogical intervention strategies are essential during this process. Collaborative work between specialists, parents, and teachers will help to obtain better results.

The activation of cognitive processes conducive to the teaching and learning process of mathematics, through the incorporation of innovative strategies with didactic material in the classroom, will allow the dyscalculic child to understand the basic concepts that lead to arithmetic calculations.

\section{Conflict of interest statement}

The authors declared that they have no competing interest.

\section{Statement of authorship}

The authors have a responsibility for the conception and design of the study. The authors have approved the final article.

\section{Acknowledgments}

The authors would like to thank the editor of IRJMIS for their valuable time, support, and advice in completing the present research. 


\section{References}

Ardila, A., \& Rosselli, M. (2007). Illiterates and cognition: The impact of education. International handbook of crosscultural neuropsychology, 181-198.

Balbi, A., \& Dansilio, S. (2010). Learning difficulties of calculus: contributions to the psychopedagogical diagnosis. Psychological Sciences , 4 (1), 7-15.

Bugden, S., \& Ansari, D. (2015). How can cognitive developmental neuroscience constrain our understanding of developmental dyscalculia. The Routledge international handbook of dyscalculia and mathematical learning difficulties, 18-43.

De-La-Peña Álvareza, C., \& Bernabéu Brotóns, E. (2018). Dyslexia and Dyscalculia: a Current Systematic Revision from a Neurogenetics Perspective. Universitas Psychologica, 17(3), 161-172.

Espinosa, A. H. R., Estevez, A. G., Roche, J. R. F., Figarola, Y. M., \& Rodriguez, D. L. (2018). Psychological intervention for development of disease awareness in addicts: Villa Colibri therapeutic community of Santiago de Cuba. International Journal of Health Sciences, 2(3), 72-80. https://doi.org/10.29332/ijhs.v2n3.232

Farnham, M. W., Wilson, P. E., Stephenson, K. K., \& Fahey, J. W. (2004). Genetic and environmental effects on glucosinolate content and chemoprotective potency of broccoli. Plant Breeding, 123(1), 60-65.

Fonseca, F., López, P. \& Massagué, L. (2019). Dyscalculia a specific learning disorder of mathematics. Scientificeducational magazine of Granma province, $\quad 15 \quad$ (1), $\quad 212-224$. https://dialnet.unirioja.es/servlet/articulo?codigo $=6840450$

Fonseca, F., López, P. \& Massagué, L. (2019). Results of the application of a strategy for the treatment of dyscalculia in primary school students. Scientific-educational magazine of Granma province, 14 (2), 64-76. https://dialnet.unirioja.es/servlet/articulo?codigo=6759652

García, N., Santana, A., Soria, B., Herrera, V. \& Vila, M. (2016). Neurospicology and neuronal bases of dyscalculia. Third virtual congress of Morphological Sciences. http://www.morfovirtual2016.sld.cu/index.php/Morfovirtual/2016/paper/viewFile/110/147

Menéndez, E. S., \& Martinez, M. E. M. (2019). Problems of learning and pedagogical intervention. International Journal of Social Sciences and Humanities, 3(2), 105-111. https://doi.org/10.29332/ijssh.v3n2.301

Meza, AKT, Freyre, JRA, Cevallos, MGO, \& Pico, MJM (2018). Autonomy, Good Humor and Support Networks, Potential of Community Resilience Intervention in People Victims of the Earthquake in the Calderón Parish. International Research Journal of Management, IT and Social Sciences , 5 (1), 1-8.

Ministry of Education of Ecuador (2016). Evaluation and Promotion Instructions for Students with Special Educational Needs. Recovered from: https://www.slideshare.net/teresitatoledorojas/instructivo-deevaluaciondeestudiantesconnee

Paramita, D. P., Adiatmika, I., Kuswardhani, T., \& Mustika, I. W. (2018). Physiological and psychosocial change and the need of health intervention model for elderly. International Journal of Health Sciences, 2(2), 61-67. https://doi.org/10.29332/ijhs.v2n2.160

Portellano, J. (2008). Child neuropsychology.

Rojas, A., Contreras, A. \& Arévalo, M., (2011). Didactic intervention to promote the learning of mathematics, in children with dyscalculia.Answers, 16(2), 5-13. https://doi.org/10.22463/0122820X.359

Roselli, M., Matute, E. (2011). The Neuropsychology of the Typical and Atypical Development of Numerical Skills.Journal of Neuropsychology, Neuropsychiatry and Neurosciences, 11(1), 123-140. https://dialnet.unirioja.es/servlet/articulo? codigo $=3640864$

Scrich, J., Cruz, L., Bembibre, D. \& Torres, I. (2017). Dyslexia, dysgraphia and dyscalculia: its consequences in education.Medical Archive Magazine of Camagüey,21(1), http://scielo.sld.cu/scielo.php?script=sci_arttext\&pid=S1025-02552017000100003\&lng=en\&tlng=en

Wiardani, N. K., Adiatmika, I., Paramita, D. P., \& Tirtayasa, K. (2018). Adult women perception towards obesity and its intervention strategies in the community. International Journal of Health Sciences, 2(2), 46-60. https://doi.org/10.29332/ijhs.v2n2.158

Zambrano, M. L. V., Barreto, M. D. L. A. C., \& Chica, T. K. M. (2018). Intervention of social work in political participation of women in forming process of neighborhood councils of canton Portoviejo. International Journal of Social Sciences and Humanities, 2(1), 134-146. https://doi.org/10.29332/ijssh.v2n1.104

Delgado, M. A. C., Delgado, R. I. Z., Palma, R. P., \& Moya, M. E. (2019). Dyscalculia and pedagogical intervention. International Research Journal of Management, IT and Social Sciences, 6(5), 95-100. 
Biography of Authors

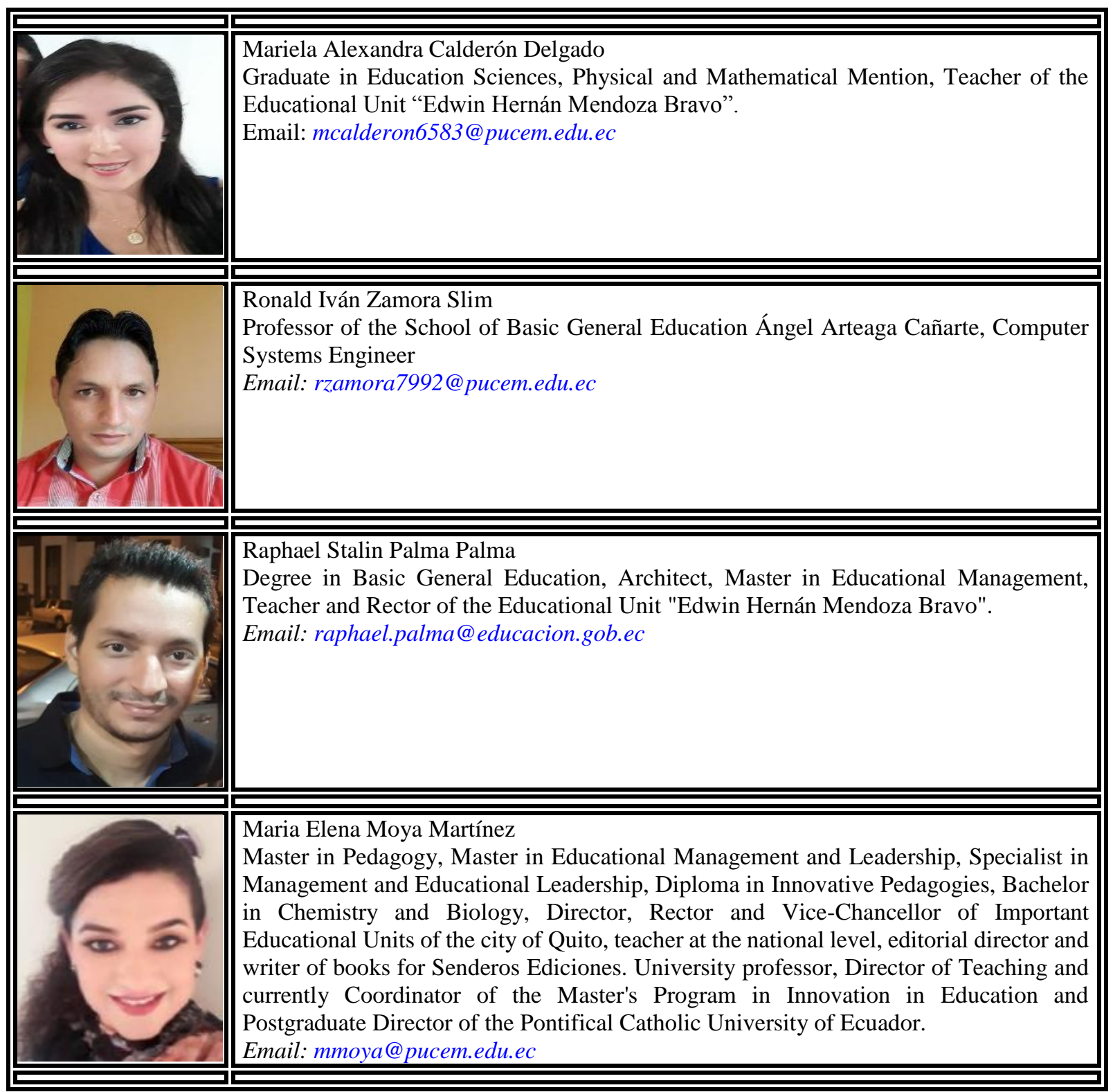

